\title{
A STUDY OF MAGNETIC AGGREGATION-GRAVITY SEPARATION FOR SEPARATION OF COARSE MAGNETITE ORES
}

\author{
ZHANG YU-SHU ${ }^{\star \dagger}$, LUO DE-ZHANG* AND LIU SHUYI* \\ ${ }^{\star}$ Mineral Processing Department, Research Institute for Multipurpose \\ Utilisation of Mineral Resources, Ministry of Geology and Mineral \\ Resources, Chengdu, Sichuan 610041, P.R. China \\ *Department of Mineral Engineering, Central South University of \\ Technology, Changsha, Hunan 410083, P.R. China
}

(Received March 14, 1996, accepted June 5, 1996)

\begin{abstract}
$\underline{\text { Abstract }}$
This paper describes experiments on separation of coarse magnetite ores using magnetic aggregation-gravity separation (MAGS) process for the first time. The results show that the MAGS technology can have a coarser separation size as well as a higher grade of the the magnetic product than the traditional low-intensity magnetic separation technology.
\end{abstract}

\section{INTRODUCTION}

Magnetic aggregation-gravity separation (MAGS) is an effective method of separating fine magnetite from gangue particles and is based on the difference in the magnetic property and specific gravity between two types of particles, i.e. differences in the magnetic force, gravity, buoyancy and the shearing force acting on particles of different characteristics in a suitable device.

\footnotetext{
$\dagger_{\text {To whom the correspondence should be addressed }}$
} 
At first, in the low-intensity magnetic field, fine magnetite particles can be magnetised and attracted into aggregates. Then these aggregates can sink at a very slow rate and get cleaned while fine gangue particles and slimes float. Finally, the magnetite aggregates become a heavy product and the fine gangue particles act as a light product, or the concentrate and tailings, respectively.

This technique was developed to efficiently reduce serious entrainment of gangue minerals in the magnetic product and to remove locked particles composed of magnetite and gangue minerals in the low-intensity magnetic separation process (LIMS) of finely disseminated magnetite ore.

MAGS has not been so far widely applied in practice. Previous laboratory tests and production practice have indicated that MAGS can be economically advantageous for treatment of finely disseminated magnetite ores, compared to traditional LIMS. As a result of inherent limitations the application of MAGS to coarse magnetite ore has yet to be studied. In view of this fact, and for the sake of a more reasonable exploration and utilisation of mineral resources, exploratory testwork on coarse V-Ti magnetite ore from Baima in Panzhihua district has been carried out using MAGS.

Samples were typical V-Ti magnetite ore from the Baima Mine-Jijiping mixture ore consisting of $23.44 \%$ of weathered ore and $76.56 \%$ of primary ore. Laboratory and pilot-plant tests were performed and the iron concentrate of $33.5 \%$ yield, $57 \% \mathrm{Fe}$ grade and approximately $69 \% \mathrm{Fe}$ recovery were obtained for particle size distribution $40 \%-76 \mu \mathrm{m}$. The concentrate was then screened. The oversize product $+0.1 \mathrm{~mm}$ contained 54.5 to $55.5 \% \mathrm{Fe}$ and can be used for smelting in a steel plant. The undersize product $-0.1 \mathrm{~mm}$ contains more than $59.0 \% \mathrm{Fe}$ and $0.75 \% \quad \mathrm{~V}_{2} \mathrm{O}_{5}$ and is the $\mathrm{V}-\mathrm{Fe}$ concentrate of a high value. MAGS increases considerably the economic benefit of the Baima $\mathrm{V}-\mathrm{Ti}$ magnetite ore and a new approach to the economical application is presently being developed.

\section{THE ORE CHARACTERISTICS}

The Baima V-Ti magnetite deposit occurs in the middle-upper part of the gabbro body. The main valuable elements in the $\mathrm{V}-\mathrm{Ti}$ magnetite ore are $\mathrm{Fe}, \mathrm{V}, \mathrm{Ti}, \mathrm{Co}$, 
$\mathrm{Ni}, \mathrm{Sc}, \mathrm{S}$ and platinum-group elements. The main gangue minerals are plagioclase, pyroxene and olivine.

The structure of the $\mathrm{V}-\mathrm{Ti}$ magnetite ore is relatively simple. The dominance is of the disseminated types, mainly medium-disseminated and sparse-disseminated structures. The secondary ore is of banded and dense-disseminated structure. The minor is a compact structure. The ore texture is sideroschisolite one. Allotropic-granular Ti-magnetite and granular ilmenite are closely intergrown, filling in the interstices among the early-crystallised gangue minerals. This part of titanomagnetite is coarse-grained, has an even contacting interface with other minerals and is easily liberated and pure aggregates can be easily obtained, and is represents mainly the minerals recovered into the $\mathrm{V}-\mathrm{Fe}$ concentrate.

Ti-magnetite of euhedral-subhedral texture is contained in coarse gangue minerals with fine grain size, small content of $\mathrm{Ti}$-magnetite is not easily liberated. This part of finely intergrown T-magnetite easily enters tailings with gangue minerals in the process of discarding coarse-grained poor mineral particles, and also easily enters the concentrate in the LIMS process and reduces the quality of the concentrate.

Size distribution of V-Ti magnetite is relatively coarse: $28.09 \%+1 \mathrm{~mm},+0.5 \mathrm{~mm}$ $78.22 \%$ and $+0.2 \mathrm{~mm} 94.0 \%$. Size distribution of the weathered ore is : $21.57 \%+1$ $\mathrm{mm}, 69.34 \%+0.5 \mathrm{~mm}$ and $90.33 \%+0.2 \mathrm{~mm}$. Therefore, fairly pure V-Fe concentrate can be obtained in the cause of coarser grinding which is a favourable factor for the application of MAGS to separation of coarse minerals.

The results of determination of the mineral characteristics have shown that $\mathrm{V}-\mathrm{Ti}$ magnetite has a fairly strong magnetic remanence $(7.00 \mathrm{G} / \mathrm{g})$, and a fairly high coercive force $(8.04 \mathrm{kA} / \mathrm{m})$. After the ore is magnetised, a rather strong remanence magnetic aggregation can be obtained even without an applied magnetic field. Although the remanence magnetic aggregation reduces the quality of the concentrate as a result of considerable entrainment of the gangue and low-grade locked particles in the LIMS process, it offers a secure guarantee for selection of the MAGS flowsheet, particularly for the remanence MAGS without the applied magnetic field. 
The main chemical components of the Jijiping mixture ore are as follows:

Fe 27.60\%, $\mathrm{Fe}_{2} \mathrm{O}_{3} 18.05 \%, \mathrm{FeO} 19.10 \%, \mathrm{TiO}_{2} 6.23 \%, \mathrm{~V}_{2} \mathrm{O}_{5} 0.27 \%, \mathrm{Cr}_{2} \mathrm{O}_{3} 0.026 \%$, Co $0.015 \%$, Ni 0.022\%, Cu 0.030\%, Mn 0.234\%, $\mathrm{SiO}_{2} 26.28 \%, \mathrm{Al}_{2} \mathrm{O}_{3} 10.88 \%, \mathrm{CaO}$ $3.72 \%, \mathrm{MgO} 8.96 \%, \mathrm{~K}_{2} \mathrm{O} 0.32 \%, \mathrm{Na}_{2} \mathrm{O} 1.49 \%, \mathrm{Ga} 0.002 \%, \mathrm{~S} 0.335, \mathrm{P} 0.053 \%$.

\section{LABORATORY TESTS}

The test results have shown that the $\mathrm{V}-\mathrm{Fe}$ concentrate of about $55.5 \% \mathrm{Fe}$ in grade and approximately $69 \% \mathrm{Fe}$ recovery can be obtained in separation of the Baima $\mathrm{V}-\mathrm{Ti}$ magnetite ore using a stage grinding-low-intensity magnetic separation flowsheet, when the feed is ground ultimately to about $56 \%-76 \mu \mathrm{m}$. If a higher quality $\mathrm{V}-\mathrm{Fe}$ concentrate with the Fe grade exceeding $59 \%$ is required, the final grinding must yield $94 \%-76 \mu \mathrm{m}$. In view of this fact, and in order to make full utilisation of the characteristics of strong magnetic remanence and high coercive force of the $\mathrm{V}-\mathrm{Ti}$ magnetite particles, which is convenient for the application of MAGS without the magnetic field induction, experimental studies using MAGS were carried out.

\section{Tests of the Grinding Fineness}

The grinding samples are from the rougher concentrate of the first-stage rod-milling-low-intensity magnetic separation of the original stage grinding-separation flowsheet with $-2.5 \mathrm{~mm}$ feed size and $40.70 \% \mathrm{Fe}$ grade. One LIMS rougher and then one MAGS cleaning of the grinding product were performed. The test results are shown in Fig. 1.

The test results have shown that with increasing fineness of the grinding, the grade of the tailings $\left(\beta_{\mathrm{x}}\right)$ is relatively constant while the grade of the concentrate $\left(\beta_{\mathrm{k}}\right)$ gradually rises. The grade of the middlings $\left(\beta_{\mathrm{n}}\right)$ slowly decreases with the decreasing feed size distribution, for size distribution of less than $49 \%-76 \mu \mathrm{m}$. However, when the concentration of particles $-76 \mu \mathrm{m}$ is higher than $49 \%$, the grade of the middlings increases sharply. The opposite is true about the recovery of the concentrate $\left(\epsilon_{\mathrm{k}}\right)$. 


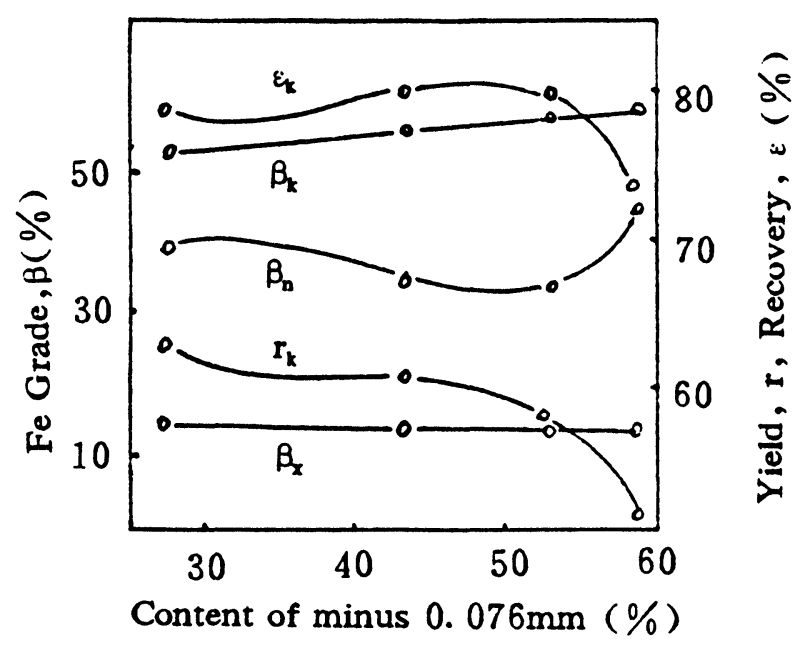

Fig. 1 The test results of the fineness of grinding. $\beta_{\mathrm{x}}$-the tailings grade, $\beta_{\mathrm{k}}$-the concentrate grade, $\beta_{\mathrm{n}}$-the middlings grade, $\epsilon_{\mathrm{k}}$-the concentrate recovery, $\mathrm{r}_{\mathrm{k}}$-the concentrate yield.

It can be seen from the results of the screen analysis of the concentrate that with increasing fineness of the grinding the grade of size fractions of the MAGS concentrate decreases which is caused mainly by the decrease of coarse magnetic carriers" and by reduction of the carrying power of water in MAGS. It is thus better to to select the grinding fineness of about $30 \%-76 \mu \mathrm{m}$ in the second-stage grinding. The MAGS concentrate is then screened using a fine screen with aperture of $0.2 \mathrm{~mm}$, and the final Fe concentrate of about $58 \% \mathrm{Fe}$ can be obtained as the undersize product. The oversize fraction and the middlings are returned together into the mill thus forming a closed circuit which constitutes the two-stage grinding-separation circuit.

\section{Tests in Grinding-Separation Circuits}

According to the results of the tests on the grinding fineness, the selected two-stage grinding-separation flowsheet is shown in Fig. 2 (flowsheet I). In order 


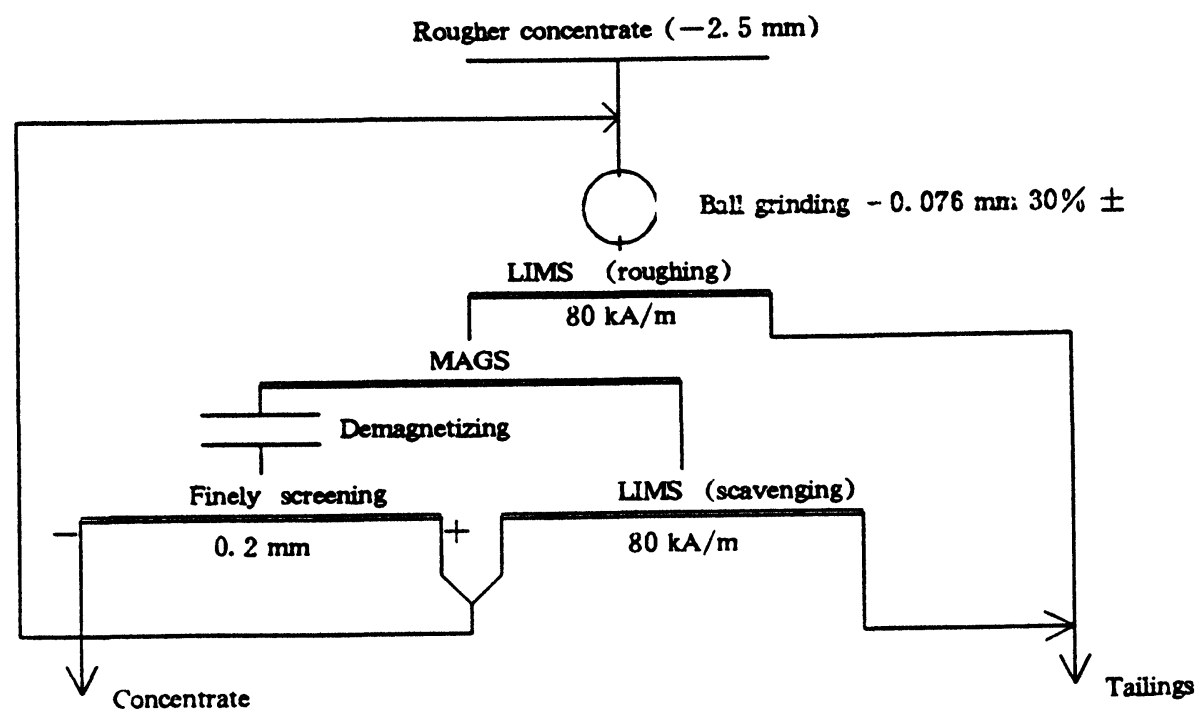

Fig. 2 The MAGS-fine screening closed circuit (Flowsheet I)

to compare with flowsheet I, experiments were carried out in low-intensity separation-fine screening closed circuit (Flowsheet II), as shown in Fig. 3, and in fine-grinding-low-intensity magnetic separation open circuit (Flowsheet III), as shown in Fig. 4 . both of these circuits have the same fineness of grinding and flowsheet structure as Flowsheet I. The results are summarised in Table 1.

Table 1 The results of the laboratory tests

\begin{tabular}{|l|c|c|c|c||}
\hline \multicolumn{1}{|c|}{ Product } & $\begin{array}{c}\text { Mass } \\
\text { yield } \\
(\%)\end{array}$ & $\begin{array}{c}\text { Grade } \\
(\% \mathrm{Fe})\end{array}$ & $\begin{array}{c}\text { Recovery } \\
(\% \mathrm{Fe})\end{array}$ & Size distribution \\
\hline Final concentrate from flowsheet I & 32.13 & 58.28 & 67.74 & $37.63 \%-0.076 \mathrm{~mm}$ \\
\hline Final concentrate from flowsheet II & 35.65 & 54.3 & 69.84 & $35.33 \%-0.076 \mathrm{~mm}$ \\
\hline Final concentrate from flowsheet III & 31.94 & 58.71 & 67.8 & $85-90 \%-0.076 \mathrm{~mm}$ \\
\hline
\end{tabular}




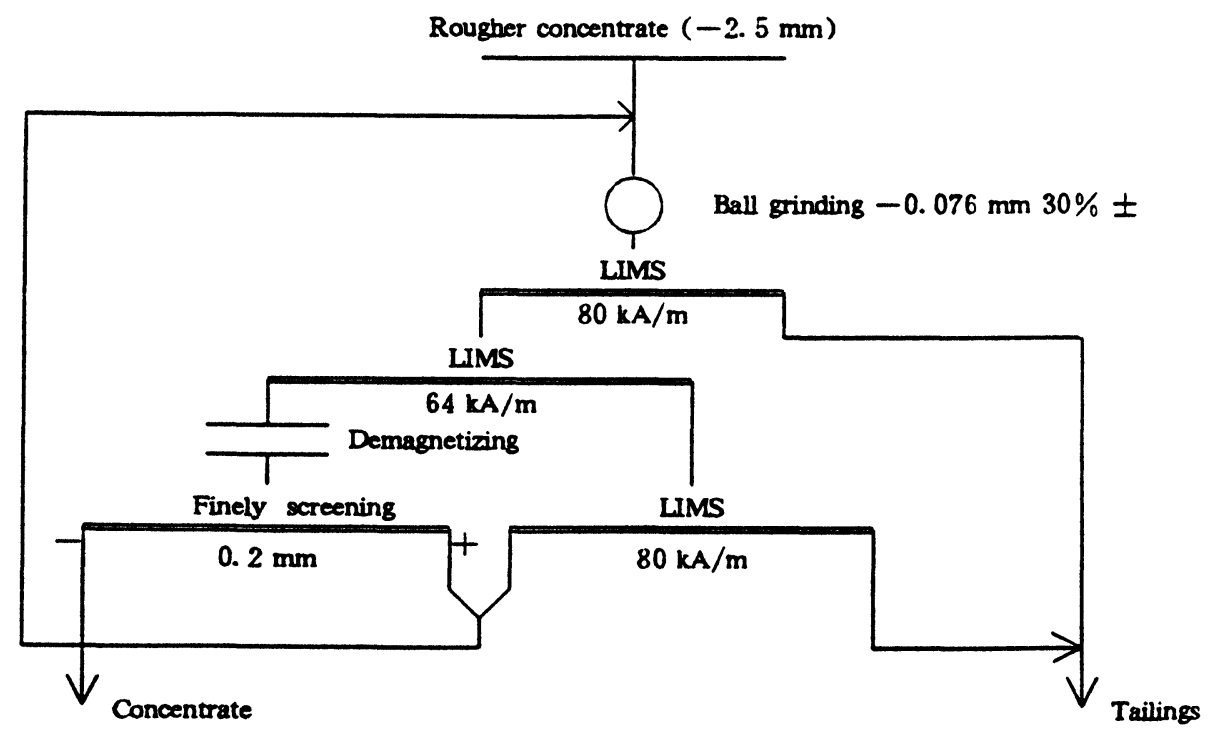

Fig. 3 Low-intensity magnetic separation-fine screening closed circuit flowsheet (Flowsheet II)

The test results have shown that, compared to low-intensity magnetic separation, the fine-screening closed circuit (flowsheet II), in the case of similar fineness of grinding, the MAGS-fine screening closed circuit (flowsheet I) can increase the grade of the $\mathrm{V}-\mathrm{Fe}$ concentrate of the Baima $\mathrm{V}-\mathrm{Ti}$ magnetite ore by $3.98 \% \mathrm{Fe}$.

Furthermore, flowsheet I (MAGS-fine screening) can generate similar results to those obtained using flowsheet III (fine grinding-low-intensity magnetic separation open circuit), the difference being that flowsheet I treats the feed which contains by $50 \%$ less particles smaller than $76 \mu \mathrm{m}$. This represents considerable energy saving. 


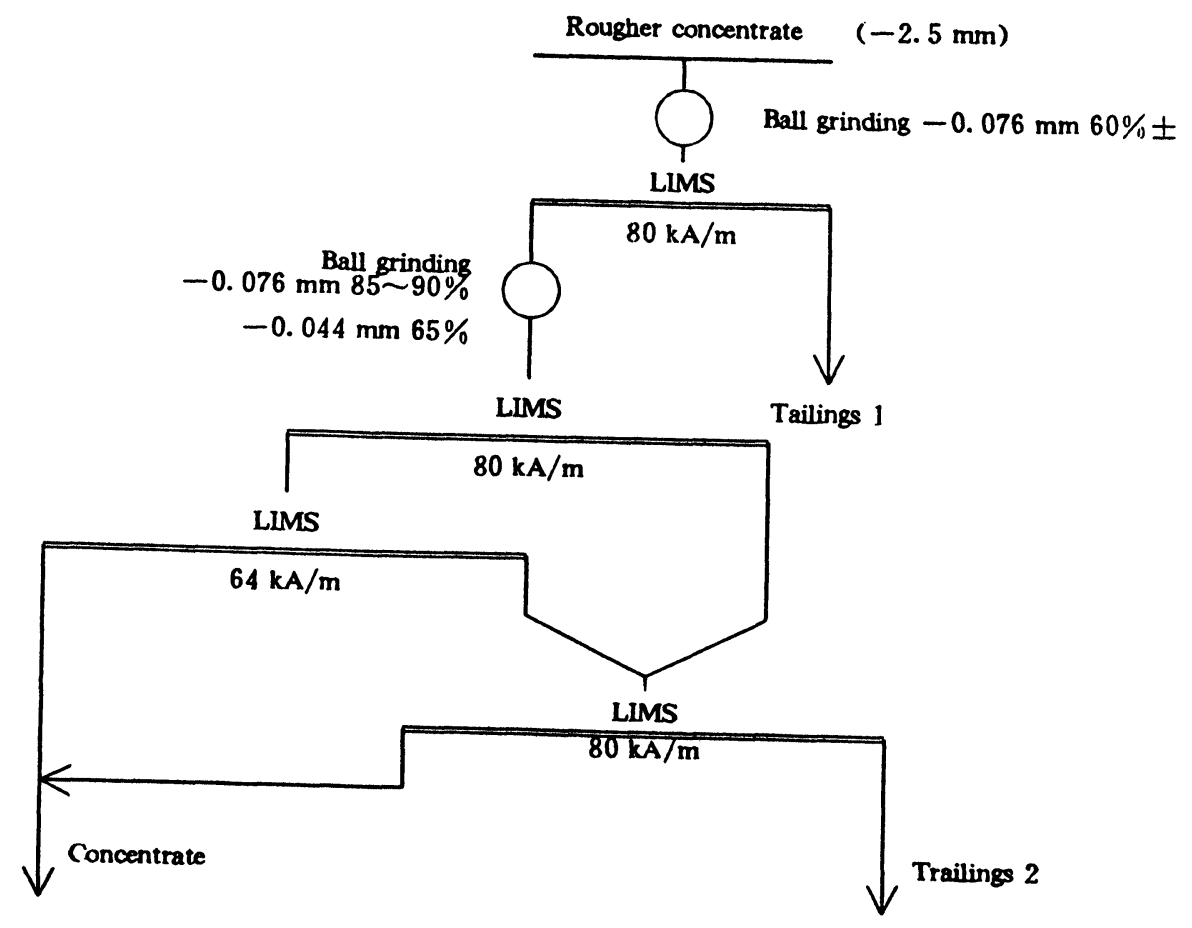

Fig. 4 Fine-grinding-low-intensity magnetic separation open circuit flowsheet (Flowsheet III).

\section{PILOT-PLANT TESTS}

In order to assess stability and reliability of MAGS for separation of coarse particles and, at the same time, to further verify the results of the laboratory tests, pilot-plant test of pre-concentration of bulk ores by stage-grinding-separation, according to flowsheets I and II were carried out.

The pilot-plant throughput was 4.39 tons and 3.19 tons per day per flowsheet, of the original ores. During the test process, the aperture size of the fine screen was increased to $0.3 \mathrm{~mm}$ and a dia. $200 \times 500$ MAGS separator (manufactured by the 
Research Institute for Multipurpose Utilisation of Mineral Resources of the Ministry of Geology and Mineral Resources) was used. The results of the pilot-plant tests are summarised in Table 2. The degrees of liberation of the concentrates are shown in Table 3. The final fineness of grinding was about $30 \%$ $-76 \mu \mathrm{m}$.

Table 2 The results of the pilot-plant tests

\begin{tabular}{|c|c|c|c|c|c|c|c|c|c|}
\hline \multirow{2}{*}{ Flowsheet } & \multirow{2}{*}{ Products } & \multirow{2}{*}{$\begin{array}{l}\text { Yield } \\
(\%)\end{array}$} & \multicolumn{5}{|c|}{ Grade $(\%)$} & \multirow{2}{*}{$\begin{array}{c}\text { Recovery } \\
(\%)\end{array}$} & \multirow{2}{*}{$\begin{array}{c}\text { Final } \\
\text { fineness }\end{array}$} \\
\hline & & & $\mathrm{Fe}$ & $\mathrm{TiO}_{2}$ & $\mathrm{~V}_{2} \mathrm{O}_{5}$ & Co & $\mathbf{N i}$ & & \\
\hline \multirow{4}{*}{ I } & Concentrate & 33.45 & 57.13 & 10.67 & 0.724 & 0.0125 & 0.0204 & 69.16 & \multirow{4}{*}{$\begin{array}{c}-0.076 \mathrm{~mm} \\
40.61 \%\end{array}$} \\
\hline & Tailings * & 50.91 & 13. 11 & 4. 45 & 0.313 & 0.0180 & 0.0249 & 24.15 & \\
\hline & Waste Stones" & 15.64 & 11.80 & 2.52 & 0.086 & 0.0071 & 0.0124 & 6.69 & \\
\hline & Feed & 100.00 & 27.63 & 6.23 & 0.272 & 0.0144 & 0.0214 & 100.00 & \\
\hline \multirow{4}{*}{ I } & Concentrate & 34.53 & 55.69 & 10.13 & 0.699 & 0.0142 & 0.0234 & 69.60 & \multirow{4}{*}{$\begin{array}{c}-0.07 b \mathrm{~mm} \\
47.13 \%\end{array}$} \\
\hline & Tailing & 49.83 & 13. 15 & 4. 69 & 0.0334 & 0.0178 & 0.0231 & 23. 71 & \\
\hline & Waste Stones & 15.64 & 11.80 & 2.52 & 0.086 & 0.0071 & 0.0124 & 6.69 & \\
\hline & Feed & 100.00 & 27.63 & 6.23 & 0.272 & 0.0144 & 0.0214 & 100.00 & \\
\hline
\end{tabular}

* Tailings consist of tailings of the first-stage and second-stage.

* Waste Stones stands for the tailings of preconcentration.

Table 3 Degree of liberation of the concentrate in flowsheets I and II (\%)

\begin{tabular}{ccccc}
\hline \multirow{2}{*}{ Flowsheet } & \multicolumn{2}{c}{ Ti-magnetites } & \multicolumn{2}{c}{ Gangue Minerals } \\
\cline { 2 - 5 } & Pure-minerals & Locked particles & Pure-minerals & Locked particles \\
\hline I & 87.09 & 12.91 & 11.74 & 88.26 \\
I & 86.25 & 13.75 & 14.22 & 85.78 \\
\hline
\end{tabular}

The final concentrate in flowsheet I was screened, the oversize fraction $+0.1 \mathrm{~mm}$ and the undersize fraction $-0.1 \mathrm{~mm}$ make up $50 \%$, respectively. The Fe grade of the oversize product is about $55 \%$ and it qualifies as a blast-furnace feed. The 
undersize product contains more than $59 \% \mathrm{Fe}$ and more than $0.75 \% \mathrm{~V}_{2} \mathrm{O}_{5}$. It is a high-value fine V-Fe concentrate. Compared with LIMS-fine screening, the capacity of the processing of the original ore increases by $39 \%$ using MAGS in the case of the same mill volume, as a result of an increase in the feed size. Under this condition, the Fe grade of the concentrate still increase by 1.61 to $2.84 \%$ and the rate of rejection of sulphides increases by more than $5.5 \%$.

In addition, in the case of this separating size, granular ilmenite and sulphides are not easily overground which is helpful for the overall recovery of the valuable components such as $\mathrm{TiO}_{2}$, Co, Ni etc., in the next stage. The MAGS method of separation of the V-Ti Baima magnetite ore is thus of considerable economic benefit.

Good reproducibility of the results of the laboratory and pilot-plant tests indicates that separation of the Baima coarse V-Ti magnetite ore by MAGS is reliable and reproducible. The results of measurement of the degree of liberation of the concentrated proved that MAGS is a new method of beneficiation of the magnetite ores. This new method possesses a higher efficiency and selectivity of separation than conventional LIMS.

\section{CONCLUSIONS}

Magnetic aggregation-gravity separation process is able to remove, with high efficiency, gangue particles containing magnetic inclusions and low-grade locked particles. Tests have shown that separation can be carried out successfully of coarse magnetite ore in the case of primary grinding size with a majority valuable minerals being liberated.

Compared with conventional LIMS technique, MAGS can increase considerably the feed size and technological and economic results of separation of the magnetite ores. Thus, the requirements of high grade, high throughput, low energy consumption and a higher economic profit can be achieved.

Successful application of MAGS to the Baima coarsely disseminated V-Ti 
magnetite ore can thus play an active role in expanding the MAGS technique and in improving the MAGS equipment.

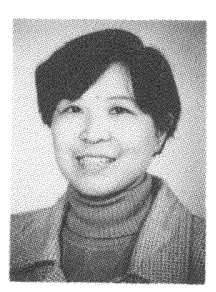

Zhang Yu-shu was born in 1962 and graduated from the Mining and Processing Department of the Kunming Engineering Institute in 1982. Since then she has been involved in research into the magnetic-aggregation-gravity separation at the Institute for Multipurpose Utilisation of Mineral Resources of the Ministry of Geology and Mineral Resources. In 1996 she was awarded M.Sc. degree from the Department of Mineral Engineering, Central South University of Technology, Changsha. During her postgraduate studies in 1993-1996 she was engaged mainly in research of the vibrating and pulsating high-gradient magnetic separation.

Luo De-zhang is a research fellow at the Institute for Multipurpose Utilisation of Mineral Resources. He is a specialist in the field of magnetic aggregation and gravity separation.

Liu Shuyi: for biography see Magn. Electr. Sep. 4 (1993), 221

Keywords: magnetic aggregation, magnetic separation, gravity separation, grinding, screening, magnetite ore 